uniform suggests that the design and material used are inappropriate.

In most accident and emergency departments the core of resuscitation teams is drawn from the staff working within the unit, and by the very nature of the emergency presentation there is often very little time to protect personal clothing and exposed skin. Not only are invasive procedures carried out in the resuscitation room but wound management elsewhere in the department results in appreciable risk of contamination. Nevertheless, it is impossible to anticipate all potential incidents, and staff are often unaware of contamination when it occurs.

An NHS report on the choice of reusable fabrics for operating theatres places emphasis on certain performance specifications which should meet British Standards. ${ }^{5}$ Synthetic fabrics of polyester, for example, are now available which meet these criteria. Protective clothing produced from such fabric acts as an efficient bacterial barrier and is liquid repellent. We are currently exploring the feasibility of providing our

\section{General practice and accident and emergency department care: does the patient know best?}

\section{Jonathan S Nguyen-Van-Tam, Daryll M Baker}

\section{Department of Accident and Emergency, University Hospital, Nottingham NG7 2UH \\ Jonathan S Nguyen-Van- \\ Tam, senior house officer \\ Daryll M Baker, senior house officer}

Correspondence to:

Dr J S Van-Tam,

Department of Public

Health Medicine and

Epidemiology, University

Hospital, Nottingham

NG7 2UH.

BMF 1992;305:157-8 medical and nursing staff with theatre-style uniforms made from this material.

This study highlights the inappropriate practice of wearing personal clothing in the accident and emergency department and the inadequate protection provided by traditional "uniforms." We recommend that accident and emergency staff should be protected by clothing of appropriate design and fabric.

We thank Mrs E MacDonald for help in preparing the manuscript.

I Skinner D, Driscoll P, Earlam R, eds. $A B C$ of major trauma. London: British Medical Journal, 1991

2 Centers for Disease Control. Update: human immunodeficiency virus infection in health care workers exposed to blood of infected patients. $M M W R$ 1987;36:285-8.

3 Centers for Disease Control. Recommendations for prevention of HIV transmission in health care settings. $M M W R$ 1987;36(suppl 2S):5-6S.

4 Wong D, Nye K, Hollis P. Microbial flora on doctors' white coats. BM 1991;303:1602-4

5 NHS Procurement Directorate. Choice of reusable fabrics for operating theatres. London: Department of Health, 1989. (NHS report STD/89/50.)

(Accepted 27 March 1992)
Accident and emergency departments function under a considerable workload. In a recent study, $12 \%$ of attendances were considered inappropriate (B Farrell et al, 35th meeting of Society for Social Medicine, 1991). Other work has shown that $8 \%$ of attenders have already consulted a general practitioner with the same problem.' If such patients are self referred, it is presumed that the general practitioner, having decided that referral to accident and emergency was unnecessary, has already given them appropriate treatment and advice. Consequently such patients often encounter scepticism from accident and emergency staff, when, in reality, little is known about them to justify such an attitude. This study considers the outcome of attendance at accident and emergency departments, comparing self referred patients who have already consulted a general practitioner with other groups.

\section{Methods and results}

For two weeks in November 1988, every tenth adult registering at our accident and emergency department was asked, before seeing a doctor, if they had already consulted a general practitioner with the same clinical problem. After treatment, case notes were examined for routinely coded clinical data, including mode of referral (self, general practitioner, workplace, etc). Cases of unconsciousness, self poisoning, and road accidents were excluded because these groups always require accident and emergency facilities. Also excluded were patients visiting the area or not registered with a local practice and those certified dead on arrival.

From 4560 sequential attenders, 442 cases were identified between 12 and 26 November 1988. Valid responses to the question were obtained from 371 $(84 \%)$.

Of the 371 respondents, 103 had already seen a general practitioner with the same problem before attending. Of these, 67 had been professionally referred, 56 by a general practitioner and 11 by other health care professionals such as a workplace nurse. The remaining 36 patients had referred themselves. Among the 268 patients who had not first seen a genera practitioner, 197 had referred themselves and 71 had been professionally referred.

The table shows the numbers of patients who were discharged, referred to outpatient clinics, or admitted as emergencies. Patients who had already seen a general practitioner before referring themselves to the accident and emergency department $(n=36)$ were jus as likely to be admitted as those in any other group. A total of 24 patients defaulted before completion of treatment (although a working diagnosis had been made by this point), but only one had seen a general practitioner before referring himself to the acciden and emergency department.

\section{Comment}

The tabulated data suggest that considerably more patients than previously recognised $(28 \%)$ attend accident and emergency departments having first seen a general practitioner. ${ }^{\prime}$ In this group $28 \%$ warranted hospital admission. Within this group, patients who had chosen to refer themselves to the accident and emergency department had done so despite having seen a general practitioner who clearly had not recommended such a course of action; none the less these patients were just as likely to require admission (34\%) Scepticism about self referred patients who have

Outcome of consultation in accident and emergency department for 371 attenders

\begin{tabular}{|c|c|c|c|c|c|c|}
\hline & $\begin{array}{c}\text { No refused or did } \\
\text { not wait }\end{array}$ & $\begin{array}{l}\text { No given formal } \\
\text { discharge }\end{array}$ & $\begin{array}{c}\text { No (\%) admitted as } \\
\text { emergency }\end{array}$ & $\begin{array}{l}\text { No given outpatient } \\
\text { appointment }\end{array}$ & Total & \\
\hline Seen by general practitioner & 1 & 46 & $29(28)$ & 27 & & 103 \\
\hline Self referred $(a)$ & 1 & 18 & $12(34)$ & 5 & 36 & \\
\hline Professionally referred (b) & & 28 & $17(25)$ & 22 & 67 & \\
\hline Not seen by general practitioner & 23 & 155 & $31(13)$ & 59 & & 268 \\
\hline Self referred $(c)$ & 18 & 119 & $15(8)$ & 45 & 197 & \\
\hline Professionally referred (d) & 5 & 36 & $16(24)$ & 14 & 71 & \\
\hline
\end{tabular}

Statistics (excluding column 1): whole table, $\chi^{2}=27 \cdot 8, \mathrm{p}=0 \cdot 0001 ;(\mathrm{a}) v(\mathrm{~b}),(\mathrm{a}) v(\mathrm{~d})$ : not significant; (a) $v(\mathrm{c}), \chi^{2}=18 \cdot 1, \mathrm{p}=0 \cdot 0001$. 
already seen a general practitioner is therefore unjustified; they are just as likely to be seriously ill as are other patients, and more so than self referred patients who have not first seen a general practitioner. Their low default rate suggests that they perceive a genuine benefit from attending the accident and emergency department.

An overlap of care due to self referral occurred in almost $10 \%$ of cases seen. In our hospital this represents 12000 attendances at the accident and emergency department each year. Such duplication raises many economic implications for purchasers and providers and the potential for problems in clinical management.
New initiatives are needed to reduce overlap while simultaneously ensuring that those with genuine needs for hospital care do not face unwarranted difficulties in gaining access.

We gratefully acknowledge the help of staff in the department of accident and emergency at the University Hospital, Nottingham

1 Davison AG, Hildrey ACC, Floyer MA. Use and misuse of an accident and emergency department in the east end of London. $\mathcal{F} R$ Soc Med 1983;76: $37-40$.

(Accepted 7 April 1992)

\section{Changing site distribution of colorectal cancer}

\author{
F Kee, R H Wilson, R Gilliland, J M Sloan, \\ B J Rowlands, R J Moorehead
}

Department of Public Health Medicine, Northern Health and Social Services Board, Ballymena BT42 1QB

F Kee, consultant

Department of Surgery, Queen's University of Belfast, Belfast R H Wilson, registrar R Gilliland, registrar B J Rowlands, professor R J Moorehead, consultant surgeon

Department of Pathology, Queen's University of Belfast

J M Sloan, reader

Correspondence to: Mr R J Moorehead, Northern Ireland Colorectal Cancer Register, Belvoir Park Hospital, Hospital Road, Belfast BT8 8JR.

BMF 1992;305: 158 population of 1.5 million.

\section{Subjects, methods, and results} Northern Ireland.
In North America and other high risk areas such as New Zealand there has been a proximal shift in the subsite distribution of colorectal cancer. ${ }^{12}$ This trend has not yet been reported in the United Kingdom. The recent establishment of the Northern Ireland Colorectal Cancer Register has allowed us to determine whether any similar change has occurred in a well defined

Demographic, clinical, and pathological data on all new histologically confirmed cases of colorectal cancer were available from the register for 1990 . Tumours were categorised as proximal if they were proximal to the splenic flexure; distal if they arose in or beyond the flexure, including the sigmoid colon; and rectal. From previous research, information was available to us on the site distribution of all histologically diagnosed tumours during 1976-78. ${ }^{3}$ In that study the site of the primary tumour had been determined from the surgical summary on the pathology request slip and from the pathology report. Mid-year population estimates were obtained from the reports of the registrar general for

Differences in the proportions of cancer at each subsite between the two periods were assessed by calculating $\chi^{2}$ statistics for contigency tables. ${ }^{4}$ Age standardised incidence was calculated by the methods of Muir et al using the world standard population.

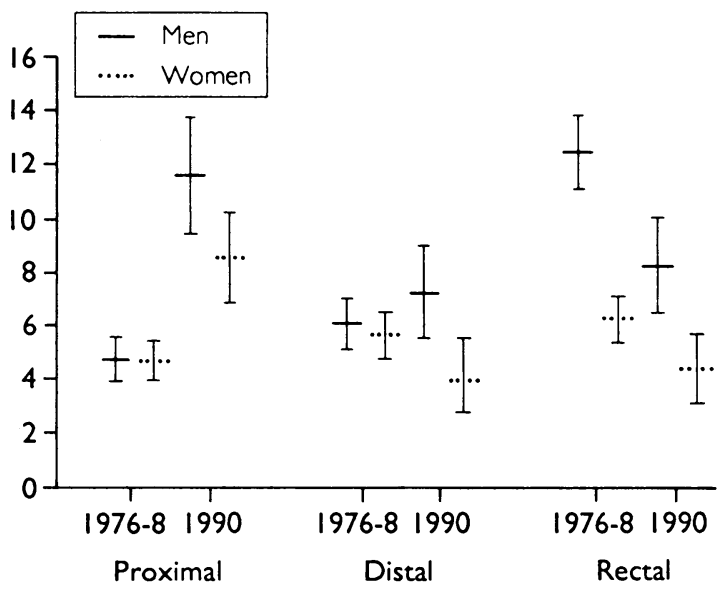

Site specific incidence of colorectal cancer, 1976-8 and 1990. Bars indicate $95 \%$ confidence intervals for age standardised incidence per 100000 population
The tumour site was unknown for 59 cases $(4 \cdot 8 \%)$ in 1976-78. The numbers of proximal, distal, and rectal tumours were $292(23 \cdot 6 \%), 339(27 \cdot 2 \%)$, and 551 $(44 \cdot 4 \%)$. In 1990 these were $231(47 \cdot 2 \%), 119(24 \cdot 4 \%)$, and $137(28 \cdot 1 \%)$, a highly significant increase in the proportion of tumours diagnosed proximal to the splenic flexure and a reduction in the proportion of tumours in the rectum $\left(\chi^{2}=62.4, \mathrm{df}=2, \mathrm{p}<0.0001\right.$, calculated assuming all unspecified tumours in the first period were proximal). There was no significant change in the overall incidence of colorectal cancer for either sex.

The figure shows the age-standardised incidence for each sex and subsite. There has been a significant increase in the absolute incidence of proximal cancers, from 4.7 to 11.6 per 100000 in men and 4.7 to 8.5 per 100000 in women. This has been accompanied by a corresponding significant decline in the incidence of rectal cancer in men, which fell from 12.5 to 8.3 per 100000 .

\section{Comment}

These changes are unlikely to be artefacts as the same primary sources of ascertainment (the pathology laboratories) were used for both periods, and the site used in the analysis was that recorded by the surgeon at operation. Given that the overall incidence of colorectal cancer has not changed significantly and that there has been a decline for distal sites, the twofold rise in proximal cancer is unlikely to be due to more frequent coincidental diagnoses consequent on the greater availability of colonoscopy.

The dietary factors that increase the risk of proximal cancer are probably different or have different thresholds from those affecting distal sites. The broadly similar rise in the incidence of proximal cancer in men and women in this study is hard to reconcile with epidemiological and metabolic evidence suggesting that responses to these factors differ for the two sexes. However, cohort effects established during a previous generation would be difficult to exclude by a study of this kind.

The Northern Ireland Colorectal Cancer Register was established with an extremely generous grant from Friends of Montgomery House and would not have been possible without the support of all the province's surgeons and pathologists.

I Beart RW, Melton J, Maruta M, Dockerty MB, Frydenberg HB, O'Fallon WM. Trends in right and left-sided colon cancer. Dis Colon Rectum 1983;26:393-8

Jass $J$. Subsite distribution and incidence of colorectal cancer in New Z Zaland 1974-83. Dis Colon Rectum 1991;34:56-9.

3 Kee F, Patterson CC, Collins BJ. Incidence and site distribution of colorectal cancer in Northern Ireland. Ulster Med f 1990,59:155-60.

4 Armitage P. Berry G. Statistical methods in medical research. 2nd ed. Oxford: Blackwell, 1987.

5 Muir C, Waterhouse T, Mack J, Powell J, Peacham D, Whelan S, et al, eds. Cancer incidence in five continents. Vol 5. Lyon: International Agency for Research on Cancer, 1987. (IARC scientific publication 88.)

(Accepted 29 April 1992 